Research Article

\title{
The Effects of Virtual Reality and Animation Supported Science Education on Students' Some Learning Products
}

\author{
Gökhan DAĞDALAN *1 (D) Erol TAŞ 2 (D) Erdem KAYA ${ }^{3}$ (D) \\ ${ }^{1}$ Ministry of Education, Ordu, Turkey, dagdalan@gmail.com \\ 2 Ordu University, Faculty of Education, Ordu, Turkey, eroltas@odu.edu.tr \\ ${ }^{3}$ Ordu University, Unye Vocational School, Ordu, Turkey, kayaerdem@hotmail.com \\ *Corresponding Author: dagdalan@gmail.com
}

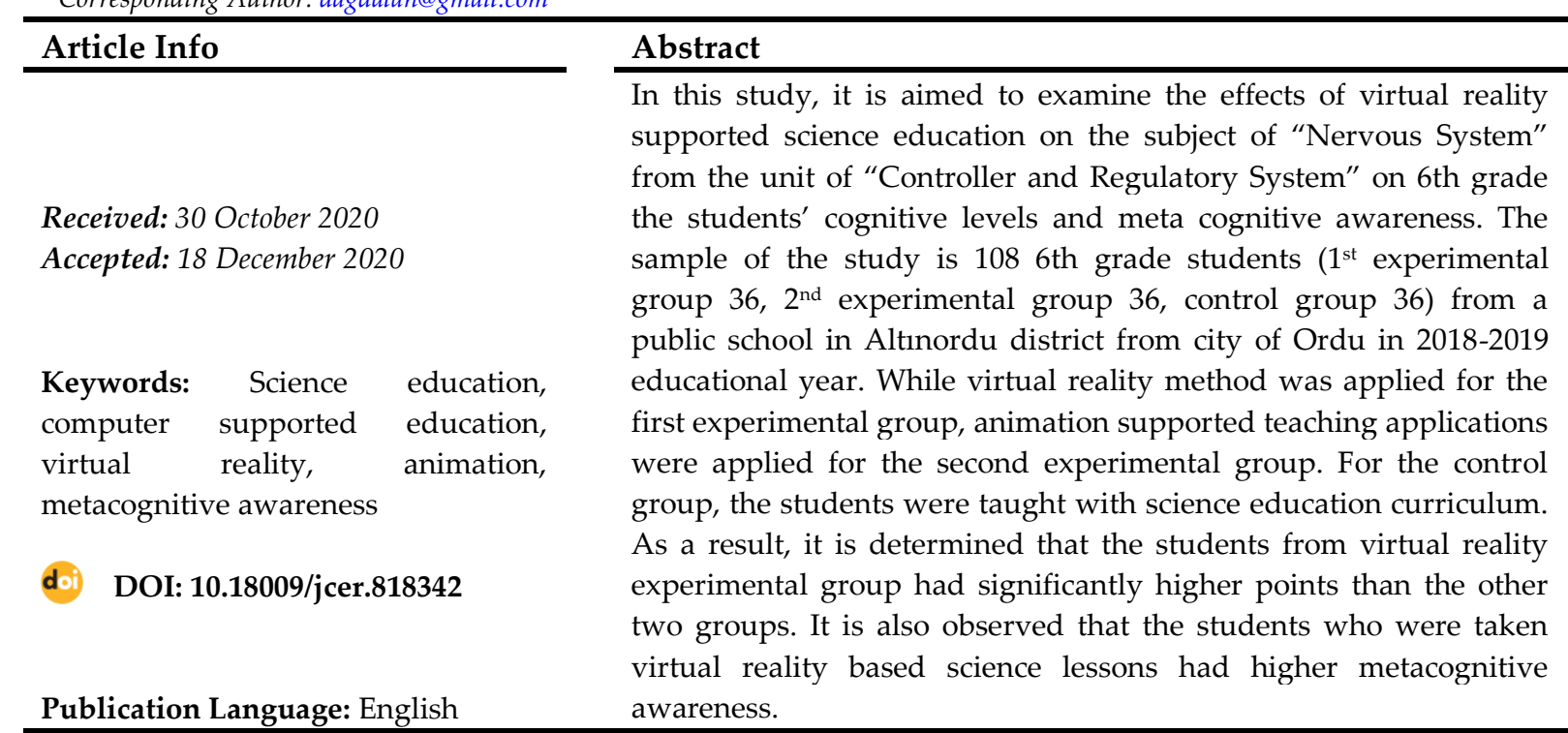

open access (

To cite this article: Dağdalan, G., Taş, E. \& Kaya, E. (2021). The effects of virtual reality and animation supported science education on students' some learning products. Journal of Computer and Education Research, 9 (17), 62-79. DOI: 10.18009/jcer.818342

\section{Introduction}

The aim of science education is to internalize the main fundamentals of science and determine the ways that would reach information by themselves, not to memorize concepts, facts and principles. Science education covers the process of acquiring abilities to get information rather than just transferring knowledge to students (Struyf, Loof, Pauw \& Petegem, 2019). Just as a scientist would do, to turn into a character who questions, explores and makes inferences by using scientific methods is among the aims of science education. Since science education subjects are difficult to understand and contain abstract subjects, teacher-centered methods that consists of transmitting information directly to students are insufficient for science teaching. This situation affects students' cognitive development adversely. The concept of metacognition refers to all of the brain activities that an individual 
does to be aware, control and organise of their own cognitive processes (Flavell, 1979). For this reason, strategies and methods which will improve individuals' cognitive levels and metacognitive awareness should be adopted. Using of technology supported teaching materials could help enhance this awareness. So, Information and Communication Technology (ICT) relates directly to education and is able to take many different roles in each phase of the process. ICT now is in indispensable position in all educational levels, at home or school, in school management and for teachers while preparing for class. Using ICT in education involves not only hardware substructure, but also educational planning, software and human resources who can use all of these efficiently. In consequence of working together well of these components, it is clear that the quality of education would increase. ICT ensures students to be more motivated and successful by positioning them actively in procedures (Kutluca, Arslan \& Özpınar, 2010; Paşa, Bolat, \& Karataş, 2015; Wakil, Rahman, Hasan, Mahmood \& Jalal, 2019; Wu, 2014). Especially with rapid developments in recent years, using technology in education has become almost an obligation. With the help of technological tools, the elusive subjects can be simplified, the experiments which are impossible to implement in classrooms can be performed, remote places which students cannot visit can be reached and intented information can be accessed instantly. Furthermore, all those activities can be made in a short period and without any life-threatining events. Students can stop being passive receivers and act active roles while learning. Under favour of technology, teachers can remove the burden of being the only basic resource and develop various teaching strategies. In addition, parents can monitor the progress of their children and design learning environments during out of school time. In this context, technology can be influential for whole learning process with better quality and feedback. One of these technological instruments is virtual reality applications.

\section{Virtual Reality}

Virtual reality is to transfer physical presence of peole or objects to computer environment via analogy (Pilgrim \& Pilgrim, 2016). These are environments which has 3D objects that users can interact with through various devices and almost feel. This kind of softwares consist of designs acting like a real world (Chandrasekera \& Yoon, 2018). They remove physical boundaries and create virtual environments which are imitations of real life (Shin, 2002). Users can construct knowledge by experiencing directly without using extra tools. Virtual reality applications have three main properties (Palmer, 2006). The first and 
most important of these is ensuring the sense of reality. The second is that the users can progress by their own request. Third one is the interaction between system and human. When compared with other applications, virtual reality softwares provide users with great interaction opportunity. In this way, user meet with an environment where he/she can construct the information when needed. Children whose abstract thinking skills are not sufficient enough have diffuculties in visualizing events. In this respect, either teacher guidance or printed materials fall behind. Technological materials enable students to visualize phenomenons. It is likely expected that a science education teaching method supported with applications designed by use of virtual reality principles increases the level of learning outcomes. Virtual reality softwares help learning through supportive hardwares by reproducing real world environment. Virtual reality applications overlap fully with the nature of science education and allow students to experience unusual virtual environments. In science education that has so much abstract and sophisticated context, students usually have troubles in meaningful and permanent learning. Even though there are various technological contents, most of them fail to produce desired effects on teaching science subjects. Virtual reality apps contribute students' abstract thinking skills and reach to information by themselves. Bayraktar and Kaleli (2007), Shin (2002) and Coruh (2011) stated that the academic success of the studdents using the virtual reality supported teaching methods was higher in their studies.

Arici (2013) is aimed to explore the effects of 3D images about astronomy subject supported by virtual reality technology on the students' academic achievement and permanence. Some activity sheets were prepared to concrete astronomy subjects on their minds. After application, it was observed that experimental group which was taught with virtual reality activities had higher points than control group. In his master thesis, Durukan (2018) assessed the effects of science environment with virtual reality applications on preservice science teachers. At the end, he mentioned that they found virtual reality softwares very useful. Topuz (2018) aimed to examine the effects of a virtual reality material on academic success. With respect to the findings, it was found that using virtual reality applications in anatomy education was more efficient. Bonner and Reinders (2018) have found that virtual reality technology helps students get meaningful learning. After implementation, students indicated that such softwares were easy to use and useful, and made them more motivated. Fung et al. (2019) have enabled students to go on a virtually 
educational trip by using virtual reality technology. It was observed that they develop positive attitudes towards virtual reality. Researcher expressed that this technology gave them a chance to make a tour to even overseas countries with low cost. In their works, Huang et al. (2019) have aimed to compare with a solar system test results between the students who had used a virtual reality and an augmented reality software designed for mobile phones. At the end of the implementation, it was concluded that the students using virtual reality technology were more successful than the ones who used augmented reality technology.

Virtual reality makes complicated basic astronomy concepts like 3D objects or planets easy to understand (Yoav, Mintz \& Litvak, 2001). Users are able to observe tiny objects and realize the light, which human brain cannot sense (Youngblut, 1998). Virtual reality materials give students a chance to visualize subjects like nervous system. With this study, unlike the works above, it is aimed to explore possible effects of a specialized virtual reality software designed for the spesific subject. The main purpose of this study is to research the effects of virtual reality supported science education applications about 6th grade Nervous System subject on students' cognitive levels and attitudes towards the students' metacognitive awareness.

\section{Method}

\section{Research Design}

On the purpose of revealing differences on academic points and metacognitive awareness, "Experimental Design With Experiment and Control Groups" method was implemented. Same teacher lectured in all three groups. She prepared a lesson plan for the unit. In guidance of the lesson plan, she carried out same activities for all groups with following course book and utilizing relevant events on Educational Informatics Network (EIN). While that method was implemented for the control group (CG), in addition to those activities, a virtual reality material was used for the first experimental group (EG1) and four animations were used for the second experimental group (EG2). Various tests were applied to obtain the quantitative data. With those tests, it was aimed to find out whether there existed any meaningful differences on cognitive levels and metacognitive awareness between the groups. With survey method, findings are represented numerically (Cepni, 2014). With this research, discovering possible changes in quantity of learning outcomes about the subject was aimed. 


\section{Sample}

The sample of the study is 108 6th grade students (1st experimental group 36, 2nd experimental group 36, control group 36) from a public school in Altinordu district from city of Ordu in 2018-2019 educational year. Simple random sampling method was used while determining the groups.

Data Collection Tools

Cognitive Level Assessment Scale (CLAS)

CLAS was developed by the researcher to specify the cognitive levels of the students. While preparing CLAS, firstly, the features of cognitive level steps were analyzed in detail. Then, the cognitive levels about "Nervous System" objectives were identified by reviewing several number of sixth grade textbooks. The first version of the scale was examined by three science education teachers and an educational expert with the purpose of ensuring content validity and not having any scientific errors. After getting feedback from the experts, the scale was put into final form for the pilot scheme. Pilot study was carried out with 132 students and KR-20 internal consistency coefficient, reliability of the scale was calculated to be .83 .

CLAS covered two achievements:

i) They represent nervous system and the tasks of central and peripheral nervous system on the model.

ii) They realize the importance of endocrine glands for human body.

It has 32 questions containing all cognitive levels. Table 1 shows the distribution of quesitons.

Table 1. Distribution cognitive levels of quesitons in CLAS

\begin{tabular}{lcc}
\hline Cognitive Level & Number of Questions & Question Number \\
\hline Knowledge & 9 & $1,2,15,16,17,18,19,20,21$ \\
Comprehension & 8 & $3,22,23,24,29,30,31,32$ \\
Application & 6 & $4,5,6,10,27,28$ \\
Analysis & 4 & $7,8,9,13$ \\
Synthesis & 2 & 11,12 \\
Evaluation & 3 & $14,25,26$ \\
\hline Total & 32 & \\
\hline
\end{tabular}


Metacognitive Awareness Scale (MAS)

MAS was used to determine level of the students' metacognitive awareness. That scale was designed firstly by Sperling et al. (2002) to evaluate metacognitive abilities. Afterwards, by working on validity, reliability and factor analysis, Karakelle and Sarac (2007) have customized the scale so that it can be usable in Turkey. Cronbach Alpha internal consistency reliability was calculated to be .64. It contains 12 factors and each one has three options as "Always", "Sometimes" and "Never".

Table 2. Design and application of experimental design with experiment and control groups

\begin{tabular}{cccc}
\hline Groups & Pre Test & Application & Post Test \\
\hline EG1 & CLAS & $\begin{array}{c}\text { Teaching with lesson plan and } \\
\text { a virtual reality application }\end{array}$ & CLAS, MAS \\
\hline EG2 & CLAS & $\begin{array}{c}\text { Teaching with lesson plan and } \\
\text { four animations software }\end{array}$ & CLAS, MAS \\
\hline CG & CLAS & Teaching with lesson plan & CLAS, MAS \\
\hline
\end{tabular}

\section{Data Analysis}

The data was analyzed with the help of SPSS 22 Packaged Software. Obtained data was analyized as factor means, standart deviations and percentage values with descriptive statistics. Before application, to detect whether data was normally distributed, Shapiro-Wilk Normality Test was applied. The scores obtained from CLAS were analyized with One Way ANOVA or Kruskall Wallis Test, which is a non-parametric test using when data was not normally distributed (Basturk, 2016). Significance level (p) was assigned to be .05. Similarly, the data from MAS was analyized with One Way ANOVA and Kruskal Wallis Test.

\section{Material}

\section{Virtual Reality Software Used in Experimental Group 1}

The researcher has made a detailed analysis on "Nervous System" subject. He has prepared a classic material for using in experimental group. Then the virtual reality version of that material was designed by a science education field expert.

Firstly, the drawings and paintings of the parts of the nervous system was done. Then, brief texts about subject were prepared and vocalized. By combining images, texts and sounds, the material was designed with the help of Unity software. In every phase of design, the researcher has always been in touch with the designer to make sure the software had no pedagogical mistakes. It was elaborated in terms of simplicity, easy to use and graphic design. 
Dağdalan, Taş \& Kaya

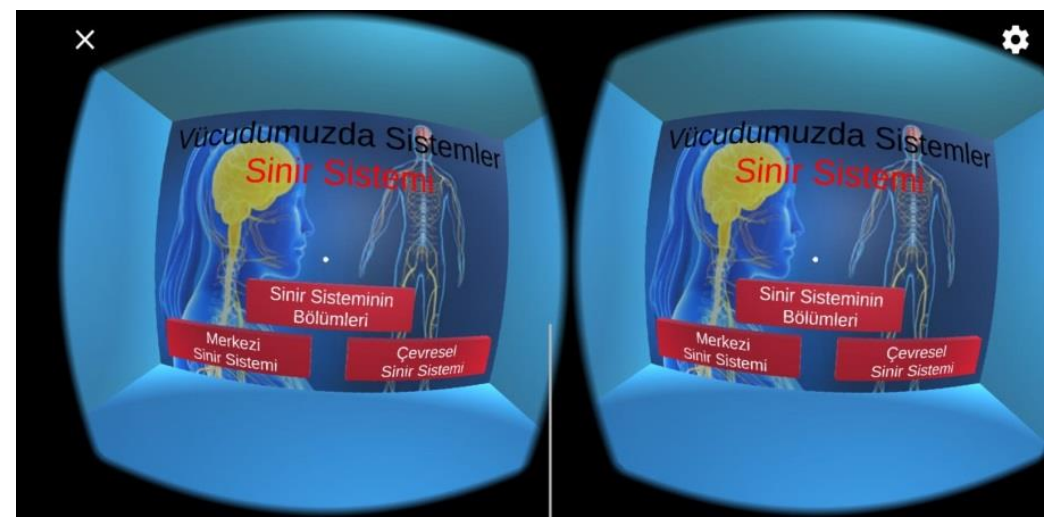

Figure 1. Virtual reality application introduction screen shot

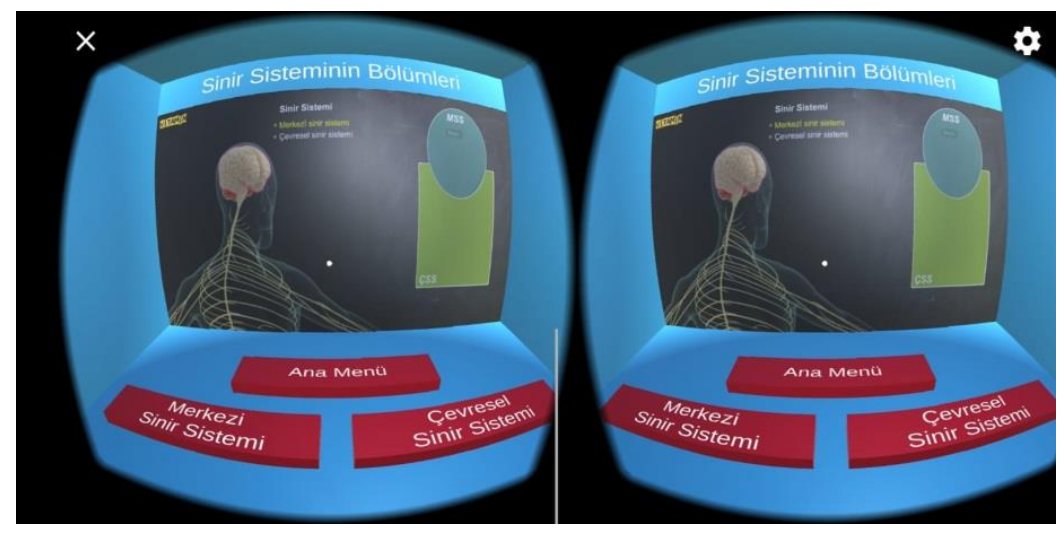

Figure 2. Parts of nervous system screen shot

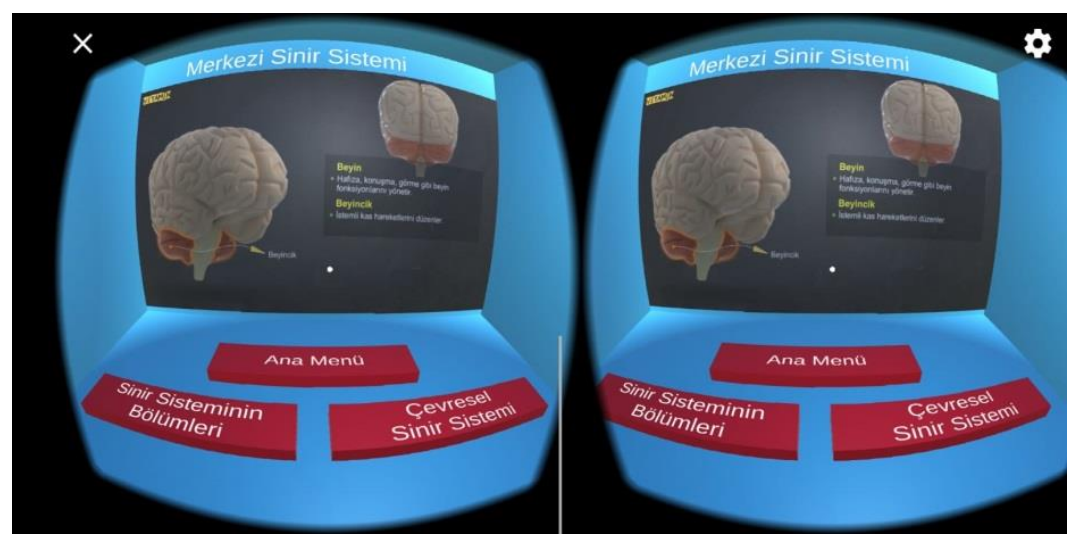

Figure 3. Central nervous system screen shot

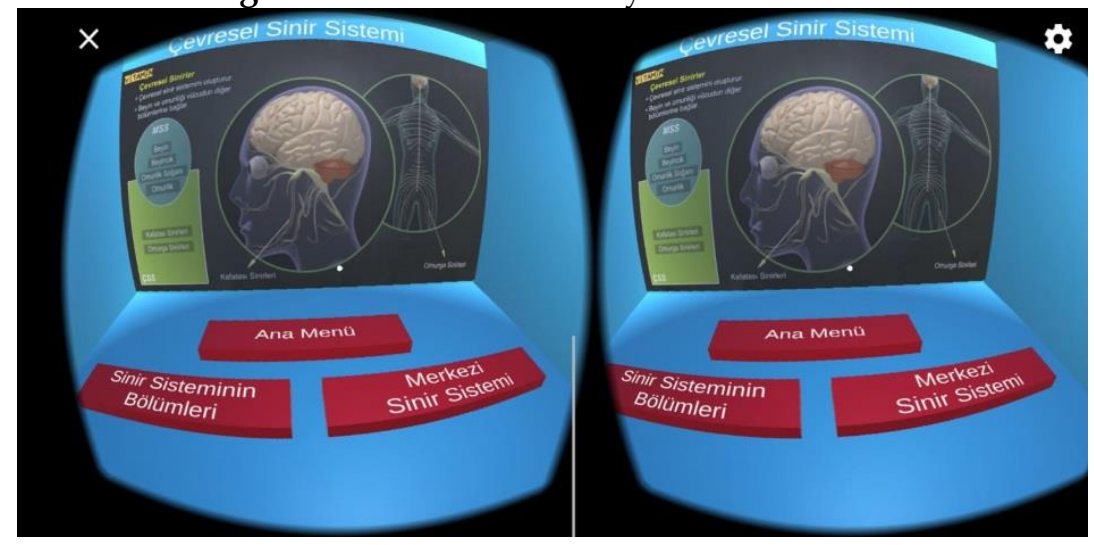

Figure 4. Peripheral nervous system screen shot 
Smart phones need gyroscope sensors to run virtual reality applications. Gyroscope is made up of a reduced friction disk which is placed on an axis in rings and pivotable easily. It is used to indicate position and direction of devices. Virtual reality applications require to have this sensor. For this reason, that software could not be run on the devices without gyroscope. It was installed on many different smart phones, which have gyroscope sensors, to make sure that it run properly.

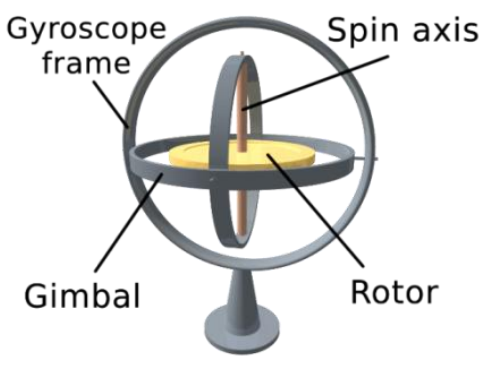

Figure 5. Gyroscope

There are numerous virtual reality headsets with different features in the market. They are seperated from each other with regard to screen size, focusing, airing, speaker, remote control, etc. In this research, virtual reality headsets with the brand of "Case $4 \mathrm{u}$ Bobo VR Z4 3D" were used.

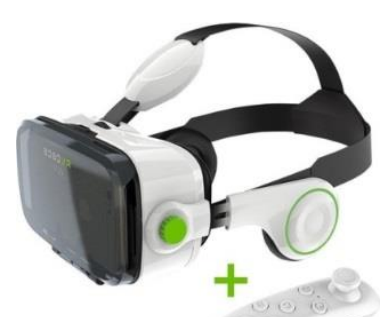

Figure 6. Case $4 \mathrm{u}$ Bobo VR Z4 3D virtual reality headset

Smart phones with screen size between $4.7^{\prime \prime}$ and 6" are suitable for these headsets. Resolution can be set with the focusing button. Thanks to adjustable belt, it can grasp user's head completely. Its ventilation system is able to avoid evaporation on screen. By help of headphones, which make easier to use in crowded environments, users can utilize without being disturbed from outside rumble.

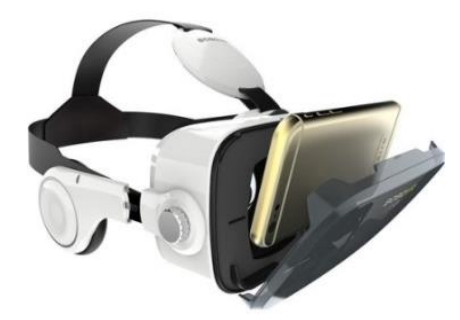

Figure 7. Mounting phone to virtual reality headset 
The QR code of the application is below.

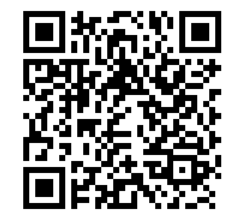

Figure 8. The QR code of applicaiton

Animation Software Used in Experimental Group 2

The animations used in research are developed by "Vitamin" (URL-1) and they match up to all objectives determined for the work. Moreover, they are published on EIN administered by Ministry of National Educaton (MNE).

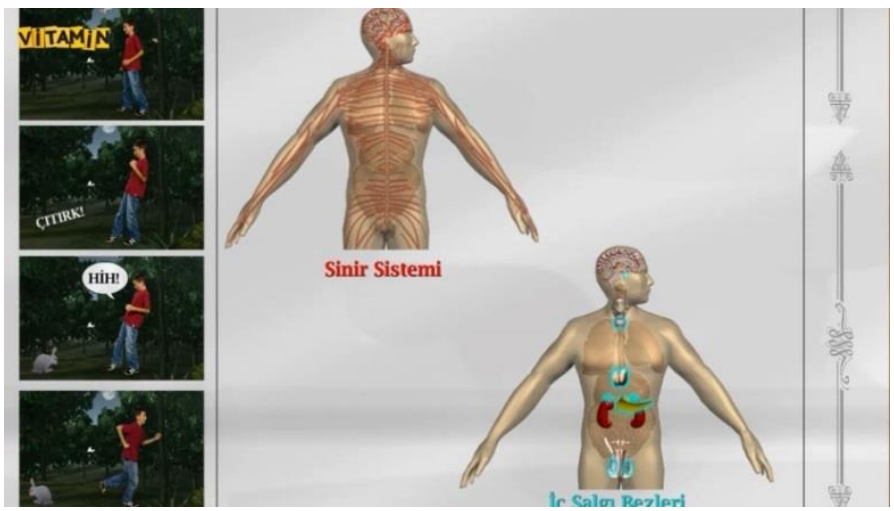

Figure 9. A screen shot from animation

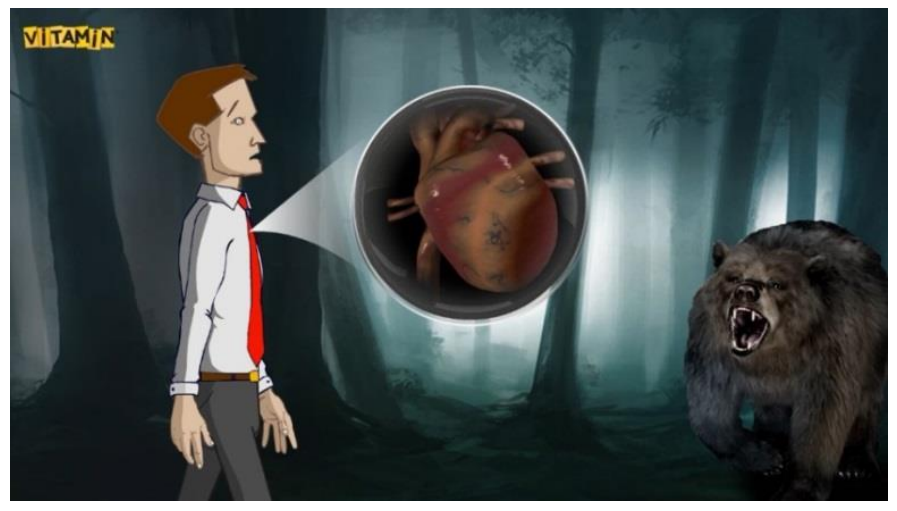

Figure 10. A screen shot from animation

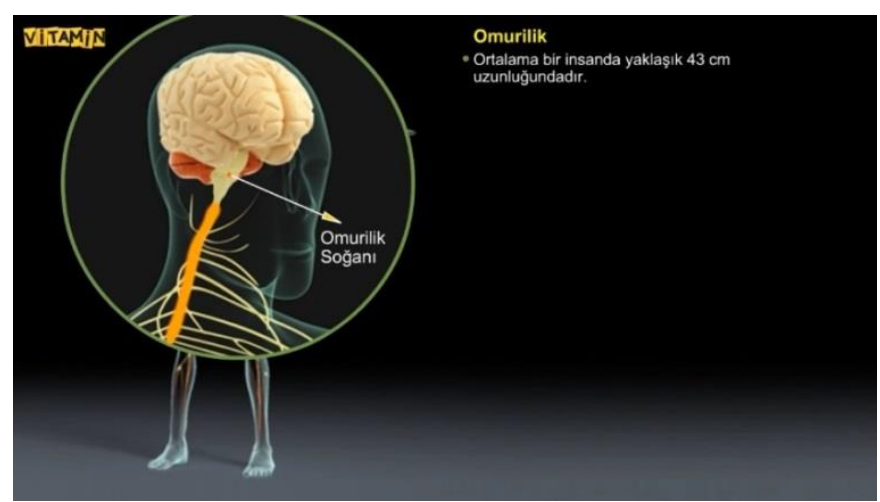

Figure 11. A screen shot from animation 


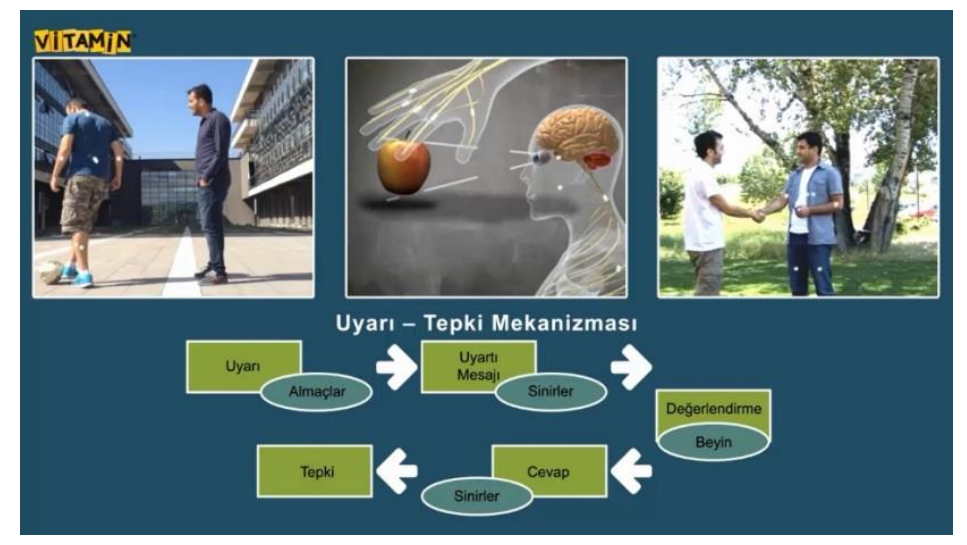

Figure 12. A screen shot from animation

\section{Control Group}

By sticking to the lesson plan, the teacher used the coursebook and some applications from EIN. She gave a lecture, asked questions and provided feedback to the students.

\section{Implementation Process}

A compatible smart phone and a virtual reality glass are required to use this material in classrooms. It is important to provide a quiet environment for hearing the sound well. In this study, the students were taken in a silent place as a group of four. They respectively experienced virtual reality software through one class hour.

\section{Findings}

The data was analyzed and presented in tables.

Table 3. Findings of Kruskal-Wallis analysis on CLAS pre-test scores of all three groups

\begin{tabular}{|c|c|c|c|c|c|c|}
\hline & & $\mathbf{n}$ & $\begin{array}{l}\text { Mean } \\
\text { Rank }\end{array}$ & sd & $X^{2}$ & $\mathrm{p}$ \\
\hline CG & \multirow{3}{*}{ Knowledge } & 36 & 50.31 & 2 & 1.87 & 0.393 \\
\hline EG1 & & 36 & 59.96 & 2 & & \\
\hline EG2 & & 36 & 53.24 & 2 & & \\
\hline CG & \multirow{3}{*}{ Comprehension } & 36 & 56.58 & 2 & 3.27 & 0.195 \\
\hline EG1 & & 36 & 59.75 & 2 & & \\
\hline EG2 & & 36 & 47.17 & 2 & & \\
\hline CG & \multirow{3}{*}{ Application } & 36 & 57.58 & 2 & 1.08 & 0.583 \\
\hline EG1 & & 36 & 50.42 & 2 & & \\
\hline EG2 & & 36 & 55.50 & 2 & & \\
\hline CG & \multirow{2}{*}{ Analysis } & 36 & 60.40 & 2 & 2.41 & 0.299 \\
\hline EG1 & & 36 & 49.86 & 2 & & \\
\hline
\end{tabular}




\begin{tabular}{|c|c|c|c|c|c|c|}
\hline EG2 & & 36 & 53.24 & 2 & & \\
\hline CG & & 36 & 54.32 & 2 & 4.08 & 0.130 \\
\hline EG1 & Synthesis & 36 & 60.81 & 2 & & \\
\hline EG2 & & 36 & 48.38 & 2 & & \\
\hline CG & & 36 & 52.50 & 2 & 1.53 & 0.466 \\
\hline EG1 & Evaluation & 36 & 57.00 & 2 & & \\
\hline EG2 & & 36 & 54.00 & 2 & & \\
\hline
\end{tabular}

When Table 3 is examined there can be seen no meaningful differences were found between any groups $(\mathrm{p}>0.05)$.

Table 4. Findings of Kruskal-Wallis analysis on CLAS Post-test scores of all three groups

\begin{tabular}{lllllll}
\hline & & $\mathbf{n}$ & $\begin{array}{l}\text { Mean } \\
\text { Rank }\end{array}$ & sd & $\mathbf{X}^{2}$ & $\mathbf{p}$ \\
\hline CG & & 36 & 57.65 & 2 & 1.37 & 0.505 \\
EG1 & Knowledge & 36 & 56.18 & 2 & & \\
EG2 & & 36 & 49.67 & 2 & & \\
\hline CG & & 36 & 56.83 & 2 & 0.34 & 0.844 \\
EG1 & Comprehension & 36 & 53.89 & 2 & & \\
EG2 & & 36 & 52.78 & 2 & & \\
\hline CG & & 36 & 44.85 & 2 & 9.94 & 0.007 \\
EG1 & Applicaiton & 36 & 51.57 & 2 & & \\
EG2 & & 36 & 67.08 & 2 & & \\
\hline CG & & 36 & 57.31 & 2 & 1.94 & 0.380 \\
EG1 & Analysis & 36 & 57.19 & 2 & & \\
EG2 & & 36 & 49.00 & 2 & & \\
\hline CG & & 36 & 59.50 & 2 & 2.01 & 0.366 \\
EG1 & Synthesis & 36 & 52.00 & 2 & & \\
EG2 & & 36 & 52.00 & 2 & & \\
\hline CG & & 36 & 55.33 & 2 & 2.42 & 0.299 \\
EG1 & Evaluation & 36 & 59.33 & 2 & & \\
EG2 & & 36 & 48.83 & 2 & & \\
\hline
\end{tabular}

With respect to Table 4, there found a significant difference only at application level $(p<0.05)$. But for the other levels, there was not any meaningful difference between all groups 
( $p>0.05)$. To find out which group has difference, Mann-Whitney U Test was applied as two groups. Table shows the findings for CG and EG1.

Table 5. Findings of Mann-Whitney U Test Between CG1 and EG1

\begin{tabular}{lllllll}
\hline & $\mathbf{n}$ & Sum of Ranks & Mean Rank & $\mathbf{U}$ & $\mathbf{Z}$ & $\mathbf{p}$ \\
\hline CG & 36 & 1360.00 & 37.78 & 602 & -0.534 & 0.593 \\
DG1 & 36 & 1268.00 & 35.22 & & & \\
Total & 72 & & & & & \\
\hline
\end{tabular}

There was no meaningful difference between CG and EG1 on application level $(\mathrm{p}>0.05)$.

Table 6. Findings of Mann-Whitney U test between CG and EG2

\begin{tabular}{lllllll}
\hline & $\mathbf{n}$ & Sum of Ranks & Mean Rank & U & Z & p \\
\hline CG & 36 & 1138.00 & 31.61 & 472 & -2.047 & 0.041 \\
DG2 & 36 & 1490.00 & 41.39 & & & \\
Total & 72 & & & & & \\
\hline
\end{tabular}

A signifcant difference was found between the control group and EG2 in favor of EG2 in favor of application level $(\mathrm{p}<0.05)$.

Table 7. Findings of Mann-Whitney U test between EG1 and EG2

\begin{tabular}{lllllll}
\hline & $\mathbf{n}$ & Sum of Ranks & $\begin{array}{l}\text { Mean } \\
\text { Rank }\end{array}$ & U & Z & p \\
\hline EG1 & 36 & 1112.50 & 30.90 & 446.500 & -2.324 & 0.020 \\
EG2 & 36 & 1515.50 & 42.10 & & & \\
Total & 72 & & & & & \\
\hline
\end{tabular}

For application level, a significant difference was found between EG1 and EG2 in favor of EG2 $(\mathrm{p}<0.05)$.

Table 8. Findings of Independent Samples ANOVA on CLAS Pre-test Academic Scores of all three groups

\begin{tabular}{|c|c|c|c|c|c|c|}
\hline Groups (I) & Groups (J) & $\mathbf{N}$ & $X$ & $\begin{array}{l}\text { Mean } \\
\text { Difference } \\
\text { (I-J) }\end{array}$ & SD & $\mathrm{p}$ \\
\hline \multirow{2}{*}{ CG } & EG1 & \multirow{2}{*}{36} & \multirow{2}{*}{11.94} & 0.167 & 0.877 & 0.982 \\
\hline & EG2 & & & 0.694 & 0.877 & 0.732 \\
\hline
\end{tabular}




\begin{tabular}{|c|c|c|c|c|c|c|}
\hline \multirow{2}{*}{ EG1 } & $\mathrm{CG}$ & \multirow{2}{*}{-36} & \multirow{2}{*}{11.78} & -0.167 & 0.877 & 0.982 \\
\hline & EG2 & & & 0.528 & 0.877 & 0.835 \\
\hline \multirow{2}{*}{ EG2 } & CG & \multirow[t]{2}{*}{36} & \multirow{2}{*}{11.25} & 0.694 & 0.877 & 0.732 \\
\hline & EG1 & & & -0.528 & 0.877 & 0.835 \\
\hline
\end{tabular}

It was found that there was no meaningful difference between any gruoups $(p>0.05)$.

Table 9. Findings of Independent Samples ANOVA on CLAS Post-test Academic Scores of all three groups

\begin{tabular}{|c|c|c|c|c|c|c|}
\hline Groups (I) & Groups (J) & $\mathbf{N}$ & $X$ & $\begin{array}{l}\text { Mean } \\
\text { Difference (I- } \\
\text { J) }\end{array}$ & SD & $\mathrm{p}$ \\
\hline \multirow{2}{*}{ CG } & EG1 & \multirow{2}{*}{36} & \multirow{2}{*}{14.69} & -1.000 & 0.950 & 0.576 \\
\hline & EG2 & & & -3.472 & 0.950 & 0.002 \\
\hline \multirow[b]{2}{*}{ EG1 } & CG & \multirow[b]{2}{*}{36} & \multirow[b]{2}{*}{15.69} & 1.000 & 0.950 & 0.576 \\
\hline & EG2 & & & -2.472 & 0.950 & 0.037 \\
\hline \multirow[b]{2}{*}{ EG2 } & CG & 36 & \multirow[b]{2}{*}{18.17} & 3.472 & 0.950 & 0.002 \\
\hline & EG1 & & & 2.472 & 0.950 & 0.037 \\
\hline
\end{tabular}

With respect to Table 9, meaningful differences existed only in favor of DG2 $(\mathrm{p}<0.05)$.

Table 10. Findings of Independent Samples ANOVA on MAS Scores of all three groups

\begin{tabular}{|c|c|c|c|c|c|c|}
\hline Groups (I) & Groups (J) & $\mathbf{N}$ & $x$ & $\begin{array}{l}\text { Mean } \\
\text { Difference } \\
(\mathrm{I}-\mathrm{J})\end{array}$ & SD & $p$ \\
\hline \multirow{2}{*}{ CG } & EG1 & \multirow{2}{*}{36} & \multirow{2}{*}{28.69} & 0.167 & 0.634 & 0.966 \\
\hline & EG2 & & & -2.306 & 0.634 & 0.002 \\
\hline \multirow{2}{*}{ EG1 } & CG & \multirow{2}{*}{36} & \multirow{2}{*}{28.53} & -0.167 & 0.634 & 0.966 \\
\hline & EG2 & & & -2.472 & 0.634 & 0.001 \\
\hline \multirow{2}{*}{ EG2 } & CG & \multirow[t]{2}{*}{36} & \multirow{2}{*}{31.00} & 2.306 & 0.634 & 0.002 \\
\hline & EG1 & & & 2.472 & 0.634 & 0.001 \\
\hline
\end{tabular}

With respect to Table 10, meaningful differences existed only in favor of DG2 $(\mathrm{p}<0.05)$ 


\section{Discussion and Conclusion}

Before the application, it was seen that the cognitive levels of both experimental and control groups were equivalent to each other according to CLAS pre-test scores. Since the students of all groups have never taken course about "Nervous System", their prior knowledge were almost the same. The groups were assigned neutrally, so that was an expected result. When we examined each cognitive levels of all students, it was observed that the data was normally distributed. Since there was no meaningful differences on all six sub-levels between the groups, it can be said that all students were at the same levels. The reasons for getting this result are such things like whole students were at the same school, the classes were assigned randomly and they had similar socio-economic features.

Except for "Application" level, the other post-test scores from CLAS were equal. In respect of analysis to identify in which group has the significant difference on "Application" level, virtual reality supported group had higher scores than two other groups. The students who use virtual reality software has thought as they have been in a 3D environment (Chandrasekera \& Yoon, 2018). The students appeared in such an efficient learning environment by seeing, hearing and staying on a virtual world. They also interacted with the software and had chance to construct knowledge (Palmer, 2006). The teacher who was a guide for application observed that they were very eager. In application level, students are expected to solve problems by adapting knowledge to new situations. The group EG1, who experienced virtual reality software with the abilities to appeal different senses, has developed on that level. This is in line with the results on improving students' problem solving skills (Bayraktar \& Kaleli, 2007; Chen, Yang, Shen \& Jeng, 2007; Shin, 2002). In addition, it matches up with the idea developed by Inhelder and Piaget (1958) that expresses students at the beginning of formal operational stage are not expected to accomplish at high level learning. With this study, it was come out that a material designed with virtual reality had been more effective than animation and classic method. There are lots of works showing similarities with the current results (Akdemir, 2009; Arici, 2013; Aslan-Efe, 2015; Cid \& Lopez, 2010; Coruh, 2011; Griol, Molina \& Callejas 2014; Huang et al., 2019; Hudson, 2010; Liou \& Chang, 2018; Topuz, 2018; Wu, Lee, Chang \& Liang, 2013). Just like the applications of these works, the students imagined as they were in a 3D enivronment. They examined closely events around and managed the process by interacting with the design. Moreover, 
having so much fun while using that material caused to keep students' motivation high and helped them comprehend the subject.

On the other hand, the studies that have come up with solutions saying using virtual reality softwares had no effect on academic achievement exist too (Esgin, Pamukcu, Ergul \& Ansay, 2011; Ozonur, 2013). Esgin et al., (2011), expressed that 3D online virtual class materials did not have any significant difference on academic success and motivation of the students. Ozonur, (2013), searched if virtual reality supported second life applicaitons had any effect on the students' grades. As a result, he observed some positive attitudes but found that those applications did not make the grades higher. The most determinant reasons for those results may be virtual reality softwares might be inappropriate with regards to content and design and lack of sense of aesthetics. The other reasons might be students' low motivations while procedure and technical inadequacy of the practitioners.

It is found out that the students who had a virtual reality material while learning had higher metacognition levels. Without having guidance or orientation from teachers, they became aware of learning by themselves. In spite of this, dominant role of the teacher like in the other groups caused students to think that they were not able to learn on their own. This result compromises with the study of Jagals and Van der Walt (2018) which tells us that students who can manage to imagine abstract concepts in their minds have higher metacognition levels. Nunaki, Damopolii, Kandowangko \& Nusantari (2019) revealed that students who are taught with inquiry-based learning method were attracted and highly motivated. They concluded that inquiry-based learning method affected metacognition levels positively. In view of the fact that virtual reality softwares attract students' attention, the results resemble to each other.

\section{Suggestions}

In consequence of this study, it was found that a virtual reality software prepared for "Nervous System" influenced students' cognitive and metacognition levels positively. Especially science education, it is suggested that virtual reality materials should be used in other diciplines. Materials with attractive visual design can be developed according to students' age and their cognitive level, for easy use and to transfer subject simply. This research was conducted with 108 sixth grade students from three different classes in a public

school. For gathering more healthy data, the number of the groups and samples can be increased. While carrying on the study, it was observed that teachers had difficulties in using 
virtual reality technology. For the next researches, guiding teacher decently on using technology is proposed. The learning outcomes, which were not tested in the study, such as permanence, learning rate and cognitive load can be examined. The affections of using virtual reality material can also be analyzed with qualitative data, not just with quantitative data. The realiability of the results can be enhanced by using different methods. Besides having a software, smart phone and virtual reality glasses are reqiured to perform this application. If schools owned these materials, it would be much easier to do. This application was developed to work only on Android operating systems. If it was designed compatible with iOS operating systems, it would be widely used. It is strongly recommended that during operation, classroom management should be ensured properly. It would be better to keep students in a silent environment if possible.

Acknowledgement

It has been confirmed by the researchers that the data used in this study are dated before 2020.

Author Contribution Statement

Gökhan DAĞDALAN: Conceptualization, methodology, measurement tool, implementation, data analysis, review-writing and editing.

Erol TAŞ: Conceptualization, methodology, consultancy and control preliminary draft writing and editing.

Erdem KAYA: Designing virtual reality material and control preliminary draft writing and editing.

\section{References}

Akdemir, A. (2009). Virtual reality technology on laparoscopic surgery instruction. Master's Thesis, Ege University, Izmir, Turkey.

Arici, V. A. (2013). A study on virtual reality softwares on science education fort the unit of "Solar System and Beyond: Space Mystery". Master's Thesis, Adnan Menderes University, Aydin, Turkey.

Aslan, Efe, H. (2015). Animasyon destekli çevre eğitiminin akademik başarıya, akılda kalıcilığa ve çevreye yönelik tutuma etkisi. Journal of Computer and Education Research, 3 (5), 120-133.

Basturk, R. (2016). Non-parametric statistical techniques with SPSS examples, Ankara, Turkey: Ani Publishing.

Bayraktar, E., \& Kaleli, F. (2007, January). Virtual reality and fields of applilcation. Academical Informatics Conference, January 31 - February 2, Kutahya, Turkey. 
Bonner, E., \& Reinders, H. (2018). Augmented and virtual reality in the language classroom: practical ideas. Teaching English with Technology, 18(3), 33-53.

Cepni. S. (2014). Introduction to research and project studies, Celebler Matbacilik, Trabzon, Turkey: Celebler Publishing.

Chandrasekera, T., \& Yoon, S. Y. (2018). Augmented reality, virtual reality and their effect on learning style in the creative design process. Design and Technology Education, 23(1), 55-75.

Chen, C. H., Yang, J. C., Shen, S., \& Jeng, M. C. (2007). A desktop virtual reality earth motion system in astronomy education. Educational Technology and Society, 10, 289-304.

Cid, C., \& Lopez, R. E. (2010). The impact of stereo display on student understanding of phases of the moon. Astronomy Education Review, 9, 1-7.

Coruh, L. (2011). Evaluation of effectiveness of virtual reality application as a learning model on Art History, Doctoral Dissertation, Gazi University, Ankara, Turkey.

Esgin, E., Pamukcu, B.S., Ergul, P., \& Ansay, S. (2011, September). The effect of using 3D online social material on students' achievement and motivation: Second Life Application. 5th International Computer ve Instructional Technologies Symposium, September 22-24, Firat University, Elazig.

Flavell, J. H. (1979). Metacognition and cognitive monitoring: a new area of cognitivedevelopmental inquiry, American Psychologist, 34(10), 906-911.

Fung, F. M., Choo, W. Y., Ardisara, A., Zimmermann, C. D., Watts, S., Koscielniak, T., Blanc, E., Coumoul, X., \& Dumke, R. (2019). Applying a virtual reality platform in environmental chemistry education to conduct a field trip to an overseas site. Journal of Chemical Education, 96(2), 382-386.

Griol, D., Molina, J. M., \& Callejas, Z. (2014). An approach to develop intelligent learning environments by means of immersive virtual worlds. Journal of Ambient Intelligence and Smart Environments, 6(2), 237-255.

Huang, K. T., Ball, C., Francis, J., Ratan, R., Boumis, J., \& Fordham, J. (2019). Augmented versus virtual reality in education: an exploratory study examining science knowledge retention when using augmented reality/virtual reality mobile applications. Cyberpsychol Behavior and Social Network, 22(2), 105-110.

Hudson, P. (2010, August). Educating EFL preservice teachers for teaching astronomy. Asia TEFL Conference, Hanoi University of Languages International Studies, August 6-8, Hanoi, Vietnam.

Jagals, D., \& Van der Walt, M. (2018). Metacognitive awareness and visualisation in the imagination: the case of the invisible circles. Pythagoras, 39(1), 1-10.

Karakelle, S., \& Sarac, S. (2007). Metacognition awareness scale for children: Study of validity and relability. Turkish Psychology Writings, 10(20), 87-103.

Kutluca, T., Arslan, S., \& Özpınar, İ. (2010). Developing a scale to measure information and communication technology utilization levels. Journal of Turkish Science Education, 7 (4), 37-45. 
Liou, W. K., \& Chang, C. Y. (2018). Virtual reality classroom applied to science education. 23rd International Scientific-Professional Conference on Information Technology (IT), 19-24 February, Žabljak, Montenegro.

Nunaki, J. H., Damopolii, I., Kandowangko, N. Y. \& Nusantari, E. (2019). The effectiveness of inquiry-based learning to train the students' metacognitive skills based on gender differences. International Journal of Instruction, 12(2), 505-516.

Ozonur, M. (2013). Designing second life softwares as virtual reality environment and exploring the effects of those softwares in terms of various variables on the students who get internet-based distance education. Doctoral Dissertation, Mersin University, Mersin, Turkey.

Palmer, D. H. (2006). Sources of self-efficacy in a science methods course for primary teacher education students. Research in Science Education, 36(4), 337-353.

Paşa, S., Bolat, Y. İ. \& Karataş, F. Ö. (2015). Changes of the chemistry teacher candidates' attitudes towards and views about information and communication technologies: chembiodraw application. Journal of Computer and Education Research, 3(6), 71-98.

Pilgrim, J. M., \& Pilgrim, J. (2016). The use of virtual reality tools in the reading-language arts classroom. Texas Journal of Literacy Education, 4(2), 90-97.

Shin, Y. S. (2002). Virtual reality simulations in Web-based science education. Computer Applications in Engineering Education, 10(1), 18-25.

Struyf, A., Haydée De Loof, Jelle Boeve-de Pauw \& Peter Van Petegem (2019). Students' engagement in different STEM learning environments: integrated STEM education as promising practice?, International Journal of Science Education, 41(10), 1387-1407.

Topuz, Y. (2018). Comparing virtual reality and 3D materials in anatomy education in terms of academic achievement and cognitive load. Master's Thesis, Marmara University, Istanbul, Turkey.

URL-1. eba.gov.tr. (Accessed: 07.08.2019)

Wakil, K., Rahman, R., Hasan, D., Mahmood, P., \& Jalal, T. (2019). Phenomenon-based learning for teaching ict subject through other subjects in primary schools. Journal of Computer and Education Research, 7 (13), 205-212. DOI: 10.18009/jcer.553507

Wu, D. (2014). An introduction to ICT in education in China: ICT in education in global context, Ed.: Huang, R., Kinshuk \& Price, J. K., Springer, Berlin, Germany, 65-84.

Wu, H. K., Lee, S. W. Y., Chang, H. Y., \& Liang, J. C. (2013). Current status, opportunities and challenges of augmented reality in education. Computers $\mathcal{E}$ Education, 62, 41-49.

Yoav, Y., Mintz, R. \& Litvak, S. (2001). 3D-virtual reality in science education: an implication for astronomy teaching. Journal of Computers in Mathematics and Science Teaching, 20(3), 293-305.

Youngblut, C. (1998). Educational uses of virtual reality technology. Virginia, USA: Institute for defense analyses alexandria va.

Copyright $\odot$ JCER

JCER's Publication Ethics and Publication Malpractice Statement are based, in large part, on the guidelines and standards developed by the Committee on Publication Ethics (COPE). This article is available under Creative Commons CC-BY 4.0 license (https://creativecommons.org/licenses/by/4.0/) 